\title{
Estudo comparativo das dimensões transversais dos arcos dentários entre jovens com oclusão normal e má oclusão de Classe II, $1^{\text {a }}$ divisão
}

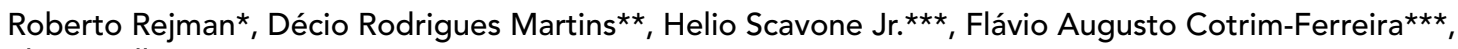

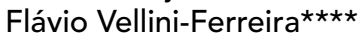

\section{Resumo}

Objetivo: avaliar as possíveis diferenças nas dimensões transversais dos arcos dentários superiores e inferiores entre jovens com oclusão normal e má oclusão de Classe II, $1^{\text {a }}$ divisão. Metodologia: foram avaliados 170 pares de modelos em gesso de jovens brasileiros leucodermas, com dentadura permanente, sendo 76 com oclusão normal (41 do gênero feminino e 35 do masculino) e média de idade de 13 anos e 6 meses e 94 com má oclusão de Classe II, $1^{\text {a }}$ divisão (58 do gênero feminino e 36 do masculino) e média de idade de 13 anos e 9 meses. Este grupo com má oclusão foi dividido em duas categorias: Classe II sem apinhamento e Classe II com apinhamento. Compararam-se as distâncias intercaninos, interprimeiros pré-molares e intermolares, em ambos os arcos dentários. Resultados: em relação ao grupo com oclusão normal, os jovens do gênero masculino evidenciaram as seguintes diferenças estatisticamente significantes: 1) distância intercaninos inferiores maior para o grupo com Classe II sem apinhamento; 2) distância interprimeiros pré-molares superiores menor para o grupo com Classe II sem apinhamento e 3) distâncias interprimeiros pré-molares e intermolares, superiores e inferiores, menores para o grupo com Classe II com apinhamento. Por sua vez, o gênero feminino evidenciou: 1) distâncias interprimeiros prémolares e intermolares superiores menores para o grupo com Classe II sem apinhamento e 2) distâncias interprimeiros pré-molares e intermolares, superiores e inferiores, menores para o grupo com Classe II com apinhamento. Conclusão: de um modo geral, os jovens com má oclusão de Classe II, $1^{\text {a }}$ divisão, apresentaram uma tendência para deficiência transversal posterior dos arcos dentários, principalmente no grupo com apinhamento.

Palavras-chave: Má oclusão. Dimensões transversais. Oclusão dentária. Ortodontia.

\section{INTRODUÇÃO}

No contexto da etiologia das más oclusões há fatores que podem causar alterações dentárias e esqueléticas múltiplas e, embora a maxila possua ossificação intramembranosa e a mandíbula ossificação mista (intramembranosa e endocondral),

\footnotetext{
* Mestre em Ortodontia pela UNICID.

** Professor Titular da Disciplina de Ortodontia da FOB-USP. Professor Associado do curso de Mestrado em Ortodontia da UNICID.

*** Professor Associado do curso de Mestrado em Ortodontia da UNICID

**** Coordenador do Curso de Mestrado em Ortodontia da UNICID.
} 
ambas sofrem influência hereditária e ambiental. Os fatores genéticos ainda não podem ser controlados, mas os fatores externos que alteram a morfologia facial e a oclusão dentária devem ser tratados, como por exemplo a respiração bucal, a sucção digital, a deglutição atípica, adenóides e tonsilas palatinas hipertrofiadas, dentre outros.

Quando o ser humano apresenta dificuldade na respiração pelo nariz, ele a complementa ou a substitui pela respiração bucal que, dependendo da freqüência, duração e intensidade, pode desencadear uma alteração na função muscular e conseqüente alteração no crescimento facial, tanto no sentido transversal como na relação sagital entre as bases ósseas.

Não existe consenso entre os pesquisadores e ortodontistas de que exista uma analogia direta entre a relação sagital de Classe II e as dimensões transversais dos arcos dentários, entretanto algumas modificações são de fácil visualização pelo ortodontista, enquanto outras apresentam-se camufladas, tornando o diagnóstico mais obscuro e até mesmo comprometendo o tratamento proposto.

A possivel discrepância transversal do arco dentário superior em pacientes com Classe II tor- na-se evidente quando a mandíbula é protruída até alcançar uma relação molar de Classe I e, neste momento, os segmentos posteriores podem apresentar mordida cruzada ${ }^{5}$.

O tratamento da má oclusão de Classe II, $1^{\text {a }}$ divisão, exige do profissional o conhecimento de todas as características possivelmente envolvidas, assim como a utilização de aparelhos ortodônticos ou ortopédicos e suas conseqüências.

Com a finalidade de elucidar qual a relação entre as dimensões transversais nos arcos dentários superiores e inferiores e a má oclusão de Classe II, $1^{\text {a }}$ divisão, esta pesquisa foi desenvolvida com o intuito de oferecer uma contribuição para um melhor diagnóstico das más oclusões.

\section{MATERIAL E MÉTODOS}

Foram avaliados 170 pares de modelos em gesso de jovens brasileiros leucodermas, com dentadura permanente e divididos em dois grupos, sendo um com oclusão normal e outro com má oclusão de Classe II, $1^{\text {a }}$ divisão.

O Grupo 1 constituiu-se de 76 pares de modelos em gesso de jovens apresentando oclusão normal na dentadura permanente (com exceção dos terceiros
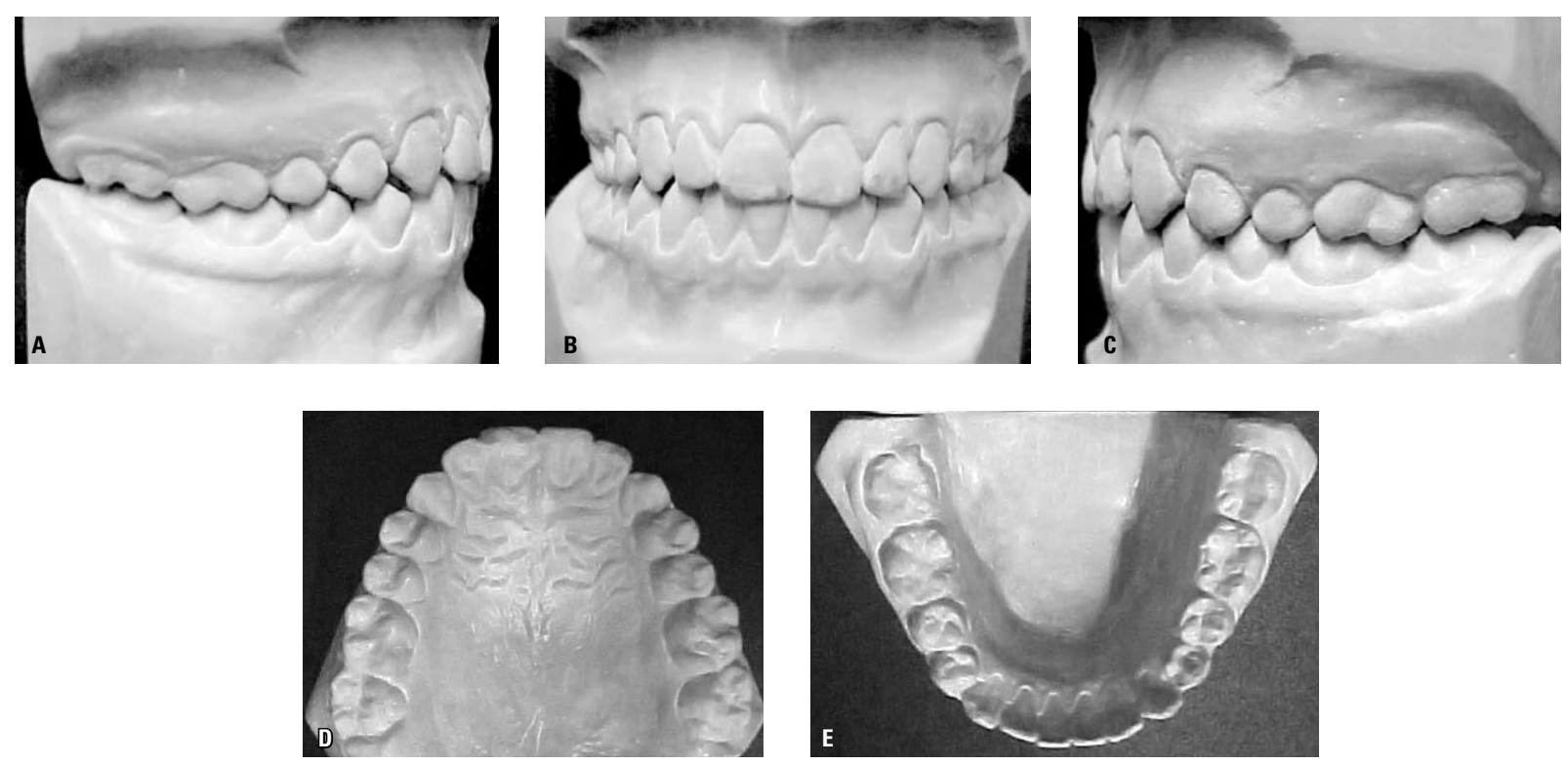

FIGURA 1 - Exemplo de um par de modelos em gesso com oclusão normal. 
molares) e sem tratamento ortodôntico, na faixa etária dos 11 anos e 11 meses aos 14 anos e 11 meses, com média de idade de 13 anos e 6 meses, sendo 41 do gênero feminino e 35 do masculino. Estes modelos encontram-se arquivados no Departamento de Ortodontia da Faculdade de Odontologia de Bauru da Universidade de São Paulo (Fig. 1).

O Grupo 2, por sua vez, englobou 94 pares de modelos em gesso apresentando má oclusão de Classe II, $1^{\text {a }}$ divisão, sendo 58 do gênero feminino e 36 do masculino, na faixa etária dos 11 anos e 4 meses aos 23 anos, com média de idade
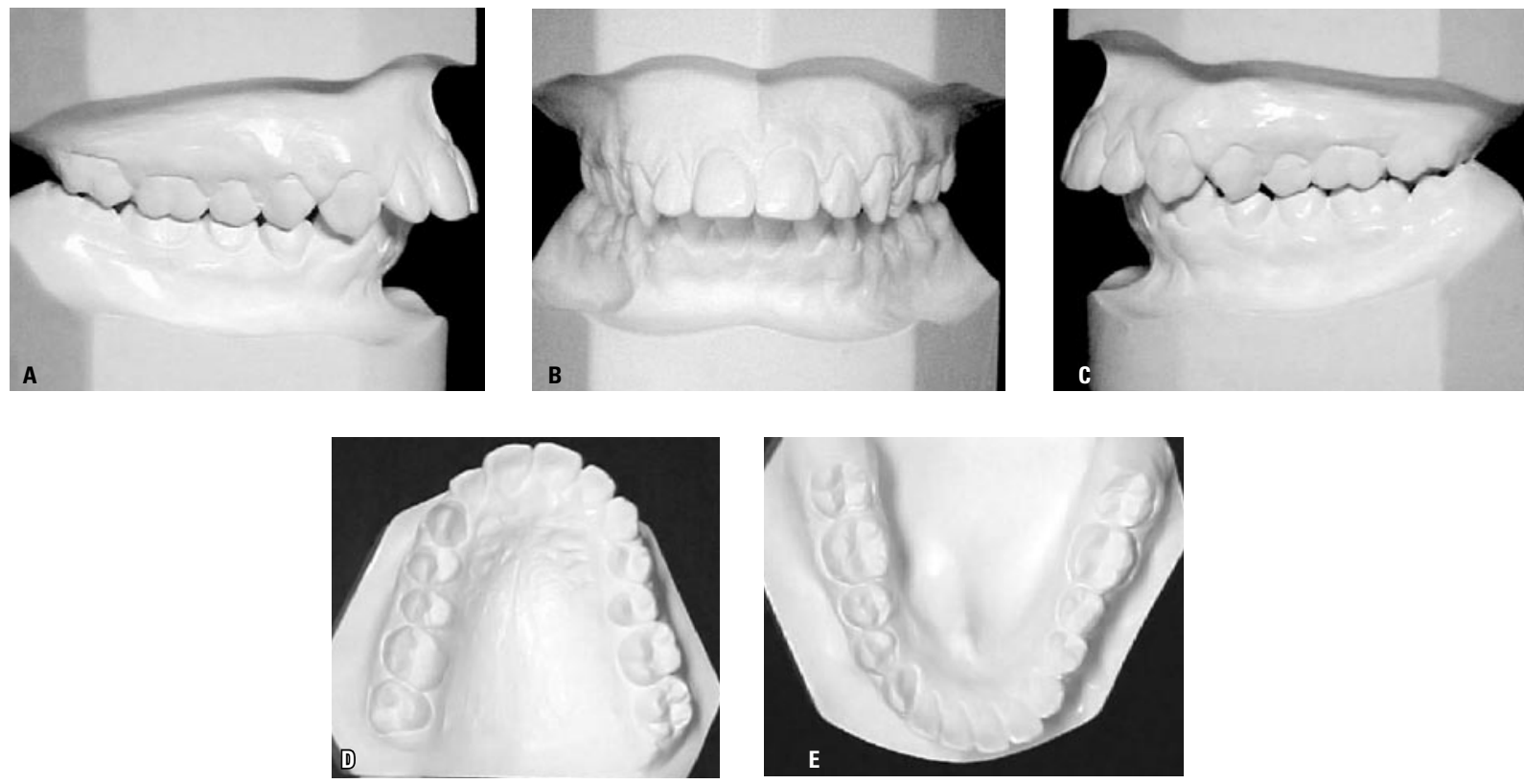

FIGURA 2 - Exemplo de um par de modelos em gesso com Classe II sem apinhamento (Classe II SA).
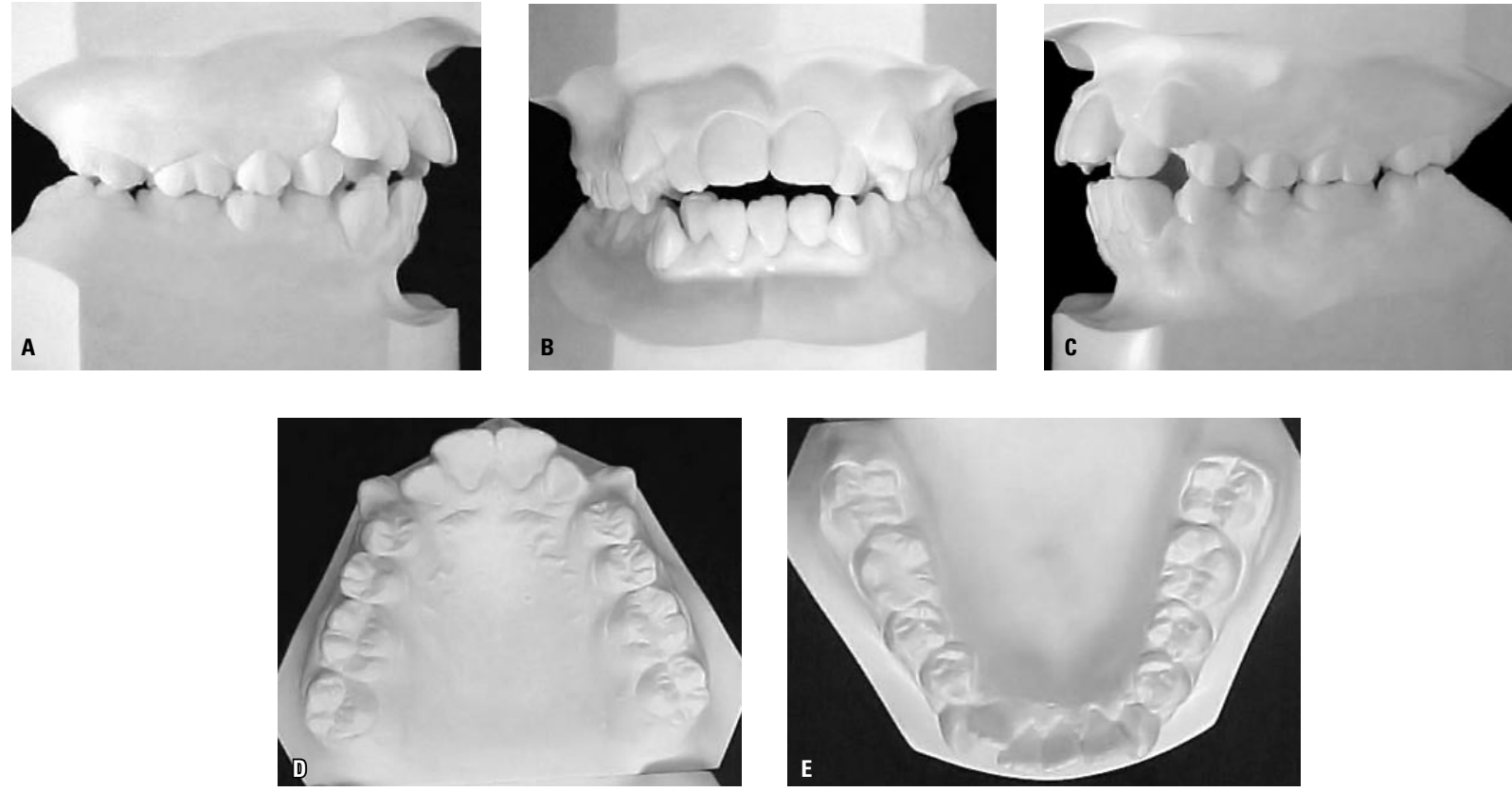

FIGURA 3 - Exemplo de um par de modelos em gesso com Classe II com apinhamento (Classe II CA). 
de 13 anos e 9 meses. Os modelos deste grupo referem-se à documentação ortodôntica de pacientes posteriormente tratados ou que ainda encontram-se em tratamento ortodôntico corretivo nos cursos de Especialização e de Mestrado em Ortodontia, da Universidade Cidade de São Paulo - UNICID, tendo sido selecionados a partir de um conjunto de 1.225 modelos, obedecendo aos seguintes critérios: 1) relação molar de Classe II bilateral; 2) dentadura permanente (com exceção dos terceiros molares); 3) ausência de mordida cruzada posterior (mesmo se limitada a um único dente); 4) ausência de agenesias ou exodontias e 5) ausência de tratamento ortodôntico prévio. Subdividiram-se os modelos deste grupo em Classe II sem apinhamento (Fig. 2) e Classe II com apinhamento (Fig. 3).

As distâncias transversais dos arcos dentários superiores e inferiores, tanto nos jovens com oclu-

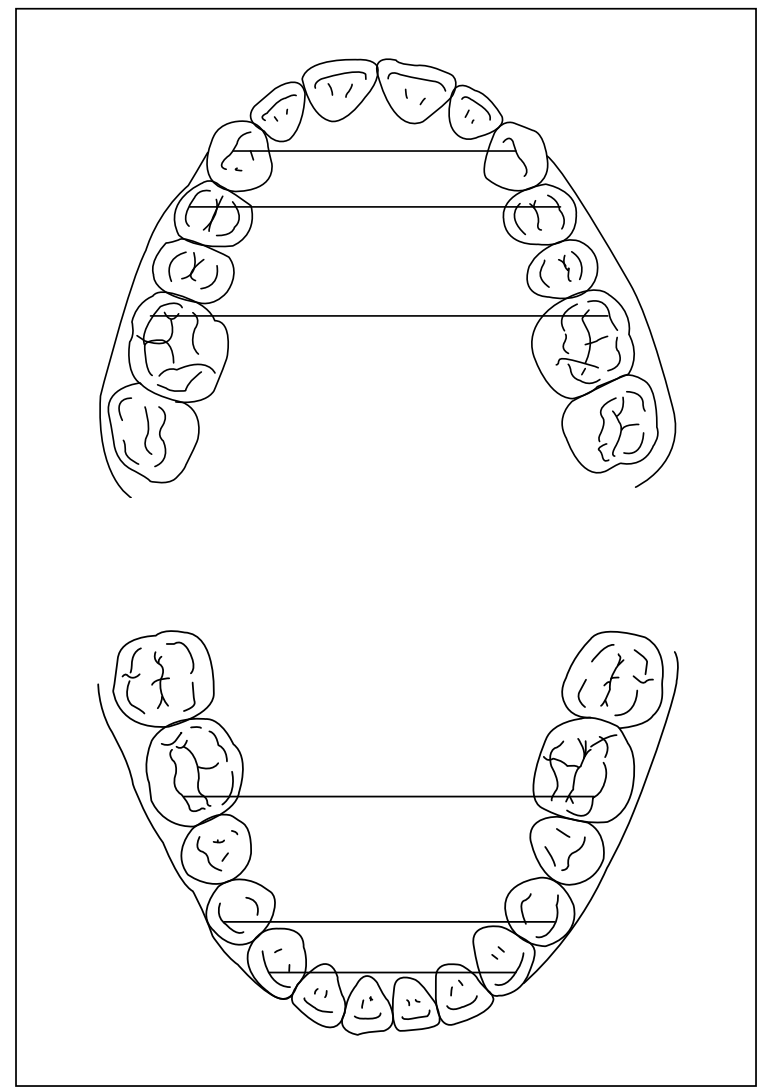

FIGURA 4 - Distâncias transversais avaliadas nos arcos superior e inferior. são normal como naqueles com Classe II, foram mensuradas em milímetros, utilizando como referência as pontas das cúspides mesiovestibulares dos primeiros molares permanentes, as pontas das cúspides vestibulares dos primeiros pré-molares e as pontas das cúspides dos caninos permanentes (Fig. 4). Para se obter as distâncias foi utilizado um paquímetro digital (Mitutoyo de $150 \mathrm{~mm}$ com margem de erro de $0,01 \mathrm{~mm}$ e código número 500-143B).

Empregou-se o teste $t$ de Student, aos níveis de $5 \%$ e $1 \%$, com o intuito de avaliar a significância estatística das comparações entre os grupos avaliados, nas seis distâncias transversais investigadas.

\section{RESULTADOS}

\section{Comparação das distâncias transversais en- tre os jovens com Classe II sem apinhamento (Classe II SA) e com oclusão normal (Tab. 1, 2)}

No gênero masculino, com exceção das distâncias intercaninos inferiores, que apresentaram valores estatisticamente maiores para o grupo com Classe II SA em relação ao grupo com oclusão normal $(\mathrm{p}<0,01)$, as demais distâncias apresentaram valores médios menores para os jovens com má oclusão, demonstrando significância estatística somente para as distâncias inter primeiros prémolares superiores $(\mathrm{p}<0,05)$.

No gênero feminino, com exceção das distâncias intercaninos inferiores, que apresentaram valores médios maiores para o grupo com Classe II SA em relação ao grupo com oclusão normal, as demais distâncias apresentaram valores médios menores para o grupo com má oclusão, demonstrando diferença estatisticamente significante para as distâncias intermolares e inter primeiros prémolares superiores $(\mathrm{p}<0,01)$.

\section{Comparação das distâncias transversais en- tre os jovens com Classe II com apinhamento (Classe II CA) e oclusão normal (Tab. 3, 4)}

Em ambos os gêneros, com exceção das dis- 
Estudo comparativo das dimensões transversais dos arcos dentários entre jovens com oclusão normal e má oclusão de Classe II, $1^{\text {a }}$ divisão

Tabela 1 - Comparação das distâncias transversais entre os grupos com Oclusão Normal e Classe II sem apinhamento (Classe II SA) no gênero masculino.

\begin{tabular}{|c|c|c|c|c|c|c|}
\hline \multirow{2}{*}{ distâncias } & \multicolumn{2}{|c|}{ oclusão normal } & \multicolumn{2}{|c|}{ Classe II SA } & \multirow{2}{*}{$\mathbf{t}$} & \multirow{2}{*}{ significância } \\
\hline & médias & d.p. & médias & d.p. & & \\
\hline intercaninos superiores & 34,80 & 1,70 & 34,26 & 1,85 & 1,02 & n.s. \\
\hline inter $1^{\circ}$ pré-molares superiores & 42,86 & 2,28 & 41,25 & 2,07 & 2,41 & * \\
\hline intermolares superiores & 53,31 & 2,87 & 51,99 & 2,76 & 1,54 & n.s. \\
\hline intercaninos inferiores & 26,46 & 1,37 & 27,54 & 1,37 & $-2,71$ & ** \\
\hline inter $1^{\circ}$ pré-molares inferiores & 35,07 & 2,01 & 34,84 & 2,30 & 0,38 & n.s. \\
\hline intermolares inferiores & 46,34 & 2,91 & 46,30 & 3,13 & 0,05 & n.s. \\
\hline
\end{tabular}

${ }^{*} p<0,05,{ }^{* *} p<0,01$, n.s. $=$ não significativo

Tabela 2 - Comparação das distâncias transversais entre os grupos com 0clusão Normal e Classe II sem apinhamento (Classe II SA) no gênero feminino.

\begin{tabular}{|c|c|c|c|c|c|c|}
\hline \multirow{2}{*}{ distâncias } & \multicolumn{2}{|c|}{ oclusão normal } & \multicolumn{2}{|c|}{ Classe II SA } & \multirow{2}{*}{$\mathbf{t}$} & \multirow{2}{*}{ significância } \\
\hline & médias & d.p. & médias & d.p. & & \\
\hline intercaninos superiores & 33,26 & 1,56 & 32,64 & 2,44 & 1,33 & n.s. \\
\hline inter $1^{\circ}$ pré-molares superiores & 41,32 & 1,86 & 39,14 & 2,71 & 4,12 & $* *$ \\
\hline intermolares superiores & 51,87 & 2,31 & 49,93 & 2,96 & 3,19 & $* *$ \\
\hline intercaninos inferiores & 25,48 & 1,21 & 26,02 & 2,19 & $-1,38$ & n.s. \\
\hline inter $1^{\circ}$ pré-molares inferiores & 34,13 & 1,67 & 33,44 & 2,43 & 1,49 & n.s. \\
\hline intermolares inferiores & 44,94 & 2,01 & 44,02 & 2,59 & 1,79 & n.s. \\
\hline
\end{tabular}

${ }^{*} p<0,05,{ }^{* *} p<0,01$, n.s. $=$ não significativo

Tabela 3 - Comparação das distâncias transversais entre os grupos com Oclusão Normal e Classe II com apinhamento (Classe II CA) no gênero masculino.

\begin{tabular}{|c|c|c|c|c|c|c|}
\hline \multirow{2}{*}{ distâncias } & \multicolumn{2}{|c|}{ oclusão normal } & \multicolumn{2}{|c|}{ Classe II CA } & \multirow{2}{*}{$\mathbf{t}$} & \multirow{2}{*}{ significância } \\
\hline & médias & d.p. & médias & d.p. & & \\
\hline intercaninos superiores & 34,80 & 1,70 & 35,64 & 3,47 & $-1,21$ & n.s. \\
\hline inter $1^{\circ}$ pré-molares superiores & 42,86 & 2,28 & 38,50 & 3,86 & 5,28 & $* *$ \\
\hline intermolares superiores & 53,31 & 2,87 & 50,23 & 3,48 & 3,15 & ** \\
\hline intercaninos inferiores & 26,46 & 1,37 & 26,72 & 2,76 & $-0,46$ & n.s. \\
\hline inter $1^{\circ}$ pré-molares inferiores & 35,07 & 2,01 & 33,45 & 2,80 & 2,43 & * \\
\hline intermolares inferiores & 46,34 & 2,91 & 44,53 & 2,85 & 2,16 & $*$ \\
\hline
\end{tabular}

${ }^{*} p<0,05,{ }^{* *} p<0,01$, n.s. $=$ não significativo

Tabela 4 - Comparação das distâncias transversais entre os grupos com 0clusão Normal e Classe II com apinhamento (Classe II CA) no gênero feminino.

\begin{tabular}{|c|c|c|c|c|c|c|}
\hline \multirow{2}{*}{ distâncias } & \multicolumn{2}{|c|}{ oclusão normal } & \multicolumn{2}{|c|}{ Classe II CA } & \multirow{2}{*}{$\mathbf{t}$} & \multirow{2}{*}{ significância } \\
\hline & médias & d.p. & médias & d.p. & & \\
\hline intercaninos superiores & 33,26 & 1,56 & 33,85 & 3,62 & $-0,91$ & n.s. \\
\hline inter $1^{\circ}$ pré-molares superiores & 41,32 & 1,86 & 37,99 & 3,01 & 5,52 & $* *$ \\
\hline intermolares superiores & 51,87 & 2,31 & 49,04 & 2,94 & 4,30 & $* *$ \\
\hline intercaninos inferiores & 25,48 & 1,21 & 26,00 & 2,53 & $-1,07$ & n.s. \\
\hline inter $1^{\circ}$ pré-molares inferiores & 34,13 & 1,67 & 32,63 & 3,02 & 2,45 & $* *$ \\
\hline intermolares inferiores & 44,94 & 2,01 & 42,55 & 2,73 & 3,76 & $* *$ \\
\hline
\end{tabular}

${ }^{*} p<0,05,{ }^{* *} p<0,01$, n.s. $=$ não significativo 


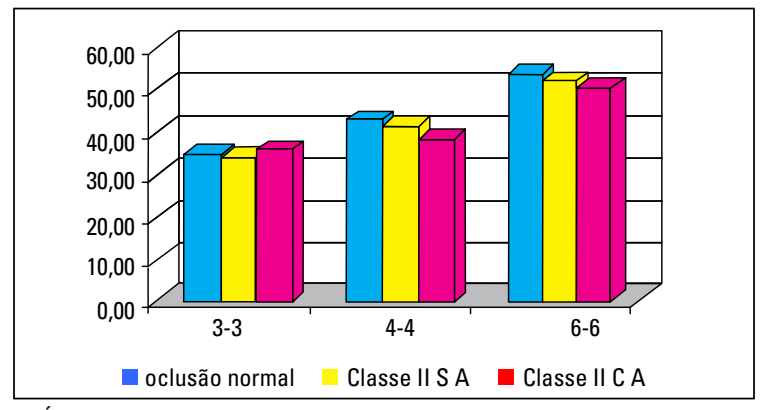

GRÁFICO 1 - Medidas transversais dos arcos dentários superiores em jovens do gênero masculino.

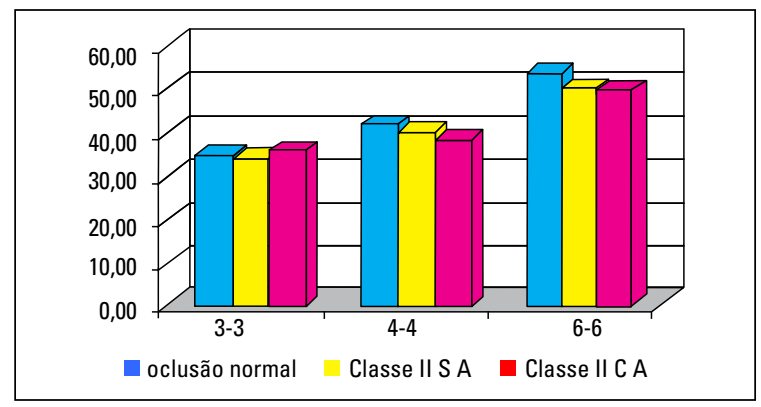

GRÁFICO 3 - Medidas transversais dos arcos dentários superiores em jovens do gênero feminino.

tâncias intercaninos, superiores e inferiores, que apresentaram valores médios maiores para o grupo com Classe II CA em relação ao grupo com oclusão normal, as demais distâncias avaliadas apresentaram valores estatisticamente menores para o grupo com má oclusão.

\section{DISCUSSÃO}

Esta pesquisa verificou que os jovens com má oclusão de Classe II apresentam uma tendência para deficiência transversal posterior em relação aos jovens com oclusão normal (Gráf. 1, 2, 3, 4). Este resultado concorda com o trabalho desenvolvido por Staley, Stuntz e Peterson ${ }^{19}$, que verificaram valores médios maiores para os jovens com oclusão normal em relação aos com Classe II.

Braun et al. ${ }^{4}$ também pesquisaram as possiveis diferenças transversais entre pacientes com Classe II e jovens com oclusão normal, observando valores menores para os jovens com má oclusão. Esse comportamento foi observado no estudo de

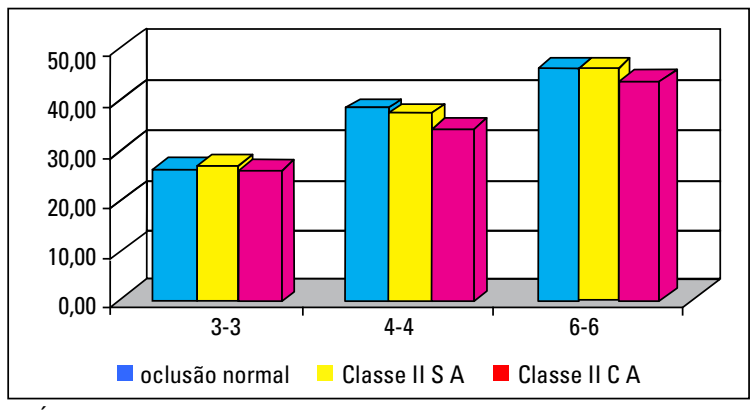

GRÁFICO 2 - Medidas transversais dos arcos dentários inferiores em jovens do gênero masculino.

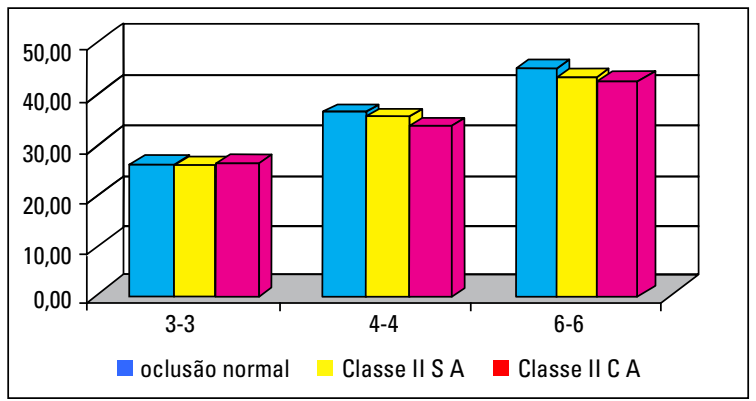

GRÁFICO 4 - Medidas transversais dos arcos dentários inferiores em jovens do gênero feminino.

Alarashi et al. ${ }^{1}$, que avaliaram telerradiografias em norma frontal e concluíram que jovens com Classe II apresentam deficiência maxilar esquelética transversal, dentária e da base nasal, quando comparados aos jovens com oclusão normal. Entretanto, discorda de Araújo e Ursi ${ }^{3}$, que não evidenciaram a existência de diferenças significantes das dimensões transversais nos arcos dentários, superiores e inferiores, entre pacientes com Classe I e Classe II com pequeno apinhamento.

Quando o fator apinhamento é avaliado, notase que os jovens com Classe II com apinhamento apresentaram deficiência transversal maxilar e mandibular mais acentuada quando comparados aos jovens sem apinhamento. Esse fato concorda com Proffit ${ }^{15}$, afirmando que as dimensões transversais afetariam diretamente o espaço disponível para o alinhamento dentário. Neste contexto, merece menção a pesquisa realizada por Howe, McNamara Jr. e O Connor ${ }^{7}$, que verificaram dimensões transversais menores em jovens com 
apinhamento em relação aos sem apinhamento.

Conforme salientou Ricketts ${ }^{17}$, a influência genética determina a base de toda a morfologia óssea, entretanto, outros fatores etiológicos poderiam explicar a deficiência transversal observada nos jovens com Classe II como, por exemplo, a respiração bucal2,8,9,10,13,16,18,20 e a sucção digital6,11,12,14,18.

\section{CONCLUSÕES}

Com base nos resultados obtidos, os autores concluíram que:

\section{No gênero masculino}

1) A distância intercaninos inferiores apresentou-se estatisticamente maior para o grupo com Classe II sem apinhamento em relação ao grupo com oclusão normal;

2) A distância interprimeiros pré-molares superiores apresentou-se estatisticamente menor para o grupo com Classe II sem apinhamento em relação ao grupo com oclusão normal;

3) As distâncias intermolares e interprimeiros pré-molares, superiores e inferiores, apresentaramse estatisticamente menores para o grupo com Classe II com apinhamento em relação ao grupo com oclusão normal.

\section{No gênero feminino}

1) As distâncias intercaninos, inferiores e superiores, não apresentaram diferença estatisticamente significante entre os grupos avaliados.

2) As distâncias intermolares e interprimeiros prémolares superiores apresentaram-se estatisticamente menores para o grupo com Classe II sem apinhamento em relação ao grupo com oclusão normal;

3) As distâncias intermolares e interprimeiros pré-molares, superiores e inferiores, apresentaramse estatisticamente menores para o grupo com Classe II com apinhamento em relação ao grupo com oclusão normal.

\title{
A comparative study of arch widths of white Brazilians with normal occlusion and Class II, Division 1, malocclusion
}

\begin{abstract}
Aim: to evaluate possible differences of the upper and lower dental arches widths among youths with normal occlusion and Class II, division 1, malocclusion. Methods: the evaluation was conducted on 170 pairs of dental casts of white Brazilian youths, with permanent dentition, 76 with normal occlusion ( 41 females and 35 males) at the mean age of 13 years and 6 months and 94 with Class II, division 1, malocclusion (58 females and 36 males) at the mean age of 13 years and 9 months. The group with malocclusion was divided into two categories: Class II without dental crowding and Class II with dental crowding. A comparison was made between the intercanine, inter first premolar and intermolar widths of both dental arches. Results: with regard to normal occlusion group and statistically significant differences, male subjects presented: 1) larger intercanine lower width in the group with Class II without crowding; 2) smaller upper inter first premolar width in the group with Class II without crowding and 3) smaller upper and lower inter first premolar and intermolar widths in the group with Class II with crowding. In turn, the females have revealed: 1) smaller upper inter first premolar and intermolar widths in the group with Class II without crowding and 2) smaller upper and lower inter first premolar and intermolar widths in the group with Class II with crowding. Conclusion: generally, the subjects with Class II, Division 1 malocclusion have presented a tendency to a posterior deficiency of dental arches widths, especially in the group with crowding.
\end{abstract}

Key words: Malocclusion. Width dimensions. Dental occlusion. Orthodontics. 


\section{REFERÊNCIAS}

1. ALARASHI, M. et al. Morphometric analysis of the transverse dentoskeletal features of Class II malocclusion in the mixed dentition. Angle Orthod, Appleton, v. 73, no. 1, p. 21-25, 2003

2. ANGLE, E. H. Classification of malocclusion. Dent Cosmos, Philadelphia, v. 41, no. 3, p. 248-264, 1899

3. ARAUJO, A. M.; URSI, W. J. S. Estudo comparativo das dimensões transversais em más oclusões de Classe I e II, de Angle. Rev Dental Press Ortodon Ortop Facial, Maringá, v. 2, n. 6, p. 69-74, nov./dez. 1997.

4. BRAUN, S. et al. The form of the human dental arch. Angle Orthod, Appleton, v. 68, no. 1, p. 29-36, 1998.

5. CAPELOZZA FILHO, L.; SILVA FILHO, O. G. Expansão rápida da maxila: considerações e aplicações clínicas. In: INTERLANDI, S. Ortodontia: bases para a iniciação. 4. ed. São Paulo: Artes Médicas, 1999. p. 285-328.

6. FUKUTA, O. et al. Damage to the primary dentition resulting from thumb and finger (digit) sucking. J Dent Child, Fulton, v. 63 , no. 6 , p. $403-407,1996$.

7. HOWE, R. P.; McNAMARA JR., J. A.; O'CONNOR, K. A. An examination of dental crowding and its relationship to tooth size and arch dimensions. Am J Orthod, St. Louis, v. 83, no. 5 , p. 363-373, 1983.

8. LANE, J. G. A study of the dynamics involved in the etiology of malocclusion. Dent Cosmos, Philadelphia, v. 59, no. 2, p.149-152, 1917.

9. MANGANELLO, L. C.; SILVA, A. A. F.; AGUIAR, M. B. Respiração bucal e alterações dentofaciais. Rev Assoc Paul Cir Dent, São Paulo, v. 56, n. 6, p. 419-422, 2002.
10. MELSEN, B. et al. Relationship between swallowing pattern, mode of respiration and development of malocclusion. Angle Orthod, Appleton, v. 57, no. 2, p. 113-120, 1987.

11. MOYERS, R. Ortodontia. 4. ed. Rio de Janeiro: Guanabara Koogan, 1991. p. 127-140.

12. NANDA, R. S.; KHAN, I.; ANAND, R. Effects of oral habits on the occlusion in preschool children. J Dent Child, Fulton, v. 39, no. 6, p. 449-452, 1972.

13. PAUL, J. L.; NANDA, R. S. Effect of mouth breathing on dental occlusion. Angle Orthod, Appleton, v. 73, no. 2, p. 201-206, 1973.

14. POPOVICH, F.; THOMPSON, G. W. Thumb and finger-sucking: its relation to malocclusion. Am J Orthod, v. 63, no. 2, p. 148-155, 1973.

15. PROFFIT, W. R. Ortodontia contemporânea. 2. ed. Rio de Janeiro: Guanabara Koogan, 1995. p. 95-123.

16. REICHENBACK, E.; BRÜCKL, H. Clinica y terapêutica ortopedicomaxilar. 1. ed. Buenos Aires: Mundi, 1971.

17. RICKETTS, R. Respiratory obstruction syndrome. Am J Orthod, St. Louis, v. 54, no. 7, p. 495-507, 1958.

18. RONDEAU, B. H. Class II malocclusion in mixed dentition. J Clin Pediatr Dent, Birmingham, v. 19, no. 1, p. 1-11, 1994.

19. STALEY, R. N.; STUNTZ, W. R.; PETERSON, L. C. A comparision of arch widths in adults with normal occlusion and adults with Class II, Division 1 malocclusion. Am J Orthod, St. Louis, v. 88, no. 2, p. 163-169, 1985.

20. UNG, N. et al. A quantitative assessment of respiratory patterns and their effects on dentofacial development. Am J Orthod Dentofacial Orthop, St. Louis, v. 98, no. 6, p. 523-532, 1990.
Endereço para correspondência

Roberto Rejman

Rua Jaci, 90 apto 53, Bloco 2 - Chácara Inglesa

CEP: 04140-080 - São Paulo/SP

E-mail: rrejman@ig.com.br 